\title{
NADİR TOPRAK ELEMENTLERINIIN HAYVAN BESLEMEDE KULLANIMI
}

Uğur SEVILMIŞ

Doğu Akdeniz Tarımsal Araştırma Enstitüsü, ADANA

\begin{abstract}
ÖZET
Nadir topraklar elementleri doğada birçok minerallerin yapısında bulunur. Günümüzde nadir toprak elementleri (NTE) tıbbi teknolojide, nükleer mühendislikte, otomobil endüstrisinde, askeri cihazlarda ve uzay araçlarında kullanılmaktadır. Ayrıca, bazı sağlık sorunlarının tedavisi için günümüzde NTE içeren ilaçlar kullanılmaktadır. Bu elementlerin gelecekteki potansiyel kullanım alanlarının kanser, osteoporoz, aterosklerozun tedavisi ve önlenmesi ile organ transplantasyonu olacağı öngürülmektedir. Çin'de NTE, on yıllardır yem katkı maddesi ve gübre olarak düşük konsantrasyonlarda başarıyla kullanılmaktadır. $\mathrm{Bu}$ ülkedeki çalışmalardan elde edilen sonuçlar, NTE kullanımının çiftlik hayvanlarında canlı ağırlık artışını ve yem dönüşümü oranını iyileştirdiğini göstermektedir. Bu elementlerin etki mekanizması iyi anlaşılmamış olmasına rağmen sindirim kanalında çok az emildiğinden, etkinliklerini bu şekilde geliştirdikleri düşünülmektedir. NTE hayvansal üretimde yeni, güvenli, ucuz bir büyüme destekleyicisi olarak ilgi çekici bir ürün durumundadır. Bu derlemenin amacı, hayvan yemlerinde nadir toprak elementi kullanımı ile ilgili elektronik olarak erişilebilir literatürü analiz etmektir.
\end{abstract}

Anahtar kelimeler: Nadir toprak elementleri, yem, hayvansal üretim

\section{THE USE OF RARE EARTH ELEMENTS IN ANIMAL NUTRITION}

\begin{abstract}
In nature, rare earths elements occur in multiple minerals. Today, they are used in medical technology, nuclear engineering, automobile industry, military devices and even in spacecraft. Furthermore, rare earth-containing drugs are used for the treatment of some health issues. In the future, among other uses, rare earths might be involved in cancer therapy, treatment and prevention of osteoporosis and atherosclerosis as well as organ transplantation. In China, rare earths have been successfully used at low concentrations as feed additives and fertilizers for decades. The results from studies from this country indicate that the use of rare earth elements improves liveweight gain and feed conversion in animals. The mechanism of action of these elements is not well understood but it is thought that they develop their activity in the digestive tract since very little is absorbed. Rare earth elements might be of interest in animal production as a new, safe and inexpensive alternative growth promoter. This review analysis the accessable literatre related to rare earth element usage in animal feed.
\end{abstract}




\section{ISSN2717-7238 ISPEC Journal of Agricultural Sciences}

Keywords: Rare earths elements, feed, animal production

\section{GİRIŞ}

Hayvansal üretimde büyüme destekleyicileri veya performans arttırıcıları dünya çapında kullanılmaktadır. Nadir toprak elementleri, periyodik cetvelde skandiyum, itriyum ve 15 adet lantanoid olmak üzere toplam 17 elementten oluşan bir gruptur. Bunları tarımda kullanmak için ilk girişimler 1970'lerde Çin'de başlamıştır (1). Çin'de nadir bulunan toprak elementlerinden lantanitlerin tuzları (lantan ve seryum), hayvansal üretimde kırk yıldan uzun süredir yem katkı maddesi olarak kullanılmaktadır (2). NTE, umut verici, doğal bir yem katkı maddesi olarak kabul edilmektedir. NTE, iyonik bağ oluşturmak için yüksek afiniteye sahiptir ki bu nedenle çok sayıda, hem organik hem de inorganik, nadir toprak elementi tuzu oluşabilir (3). Çin'de NTE, on yıllardır sadece yem katkı maddesi olarak değil, aynı zamanda gübre olarak da düşük konsantrasyonlarda başarıyla kullanılmaktadır. Çin'de kullanılan yem katkı maddeleri ağırlıklı olarak hafif NTE olan La, Ce, Pr ve Nd içerir. Hem organik (nitratlar, klorürler vb.) hem de inorganik (askorbatlar, sitratlar vb.) NTE yem katkı maddeleri ticari olarak mevcut olsa da, organik olanlar daha iyi sonuçlar verdiğini bildirilmektedir. Lancer isimli, NTE içeren yem katkı maddeleri, İsviçre'de domuz üretimindeki kullanım için geçici izin alarak pazara girmiştir. Tekli NTE yerine NTE karışımıyla daha iyi etkiler elde edildiği rapor edilmiştir (3). Şu anda, veterinerlik uygulamalarında, NTE hayvan sağlığını ve üretimini iyileştirmek için yeni yem katkı maddeleri olarak tanıtımı yapılmış ürünlerdir (4). 2016 yılında, AB'de ilk NTE bazlı yem katkı maddesine, sütten kesilmiş domuz yavruları için zooteknik bir katkı maddesi olarak, izin verilmiştir (5).

Çin kaynaklı literatürlerde yer alan çok sayıda rapor, yemde az miktarda NTE karışımının domuz, sığır, koyun ve tavukların sadece canlı ağırlık kazanımlarını değil aynı zamanda süt ve yumurta üretimini artırdığını göstermektedir (2). Sonuçlar, NTE'nin özellikle klorürler yerine daha etkili olan organik tuzlar olarak beslendiğinde, yavru domuz için iyi bir yem takviyesi olabileceğini göstermiştir. Besi domuzlarının beslenmesinde kullanımı da iyi sonuçlar vermiştir. Kanatlı hayvan beslemede, NTE domuz yavrularında olduğu kadar umut verici değildir. Sınırlı sayıda gerçekleştirilen denemeler temelinde kesin sonuçlar çıkarmak zordur, ancak kümes hayvanlarının beslenmesinde NTE kullanımındas sitratlar, klorürlerden daha iyi sonuçlar vermektedir (1).

\section{Year 1/ 2017, Volume-1, Issue-1 | https://ispecjournal.com}




\section{ISSN2717-7238 ISPEC Journal of Agricultural Sciences}

Kadmiyum, civa ve kurşun gibi diğer ağır metallere benzeyen NTE'nin toksisite riski, beslenme kanalında düşük emilimi nedeniyle sınırlıdır (1). Genel olarak, oral yoldan tatbik edilen NTE emilimi çok düşüktür ve hayvan dışkısından \% 95'inden fazlası geri kazanılmaktadır. Çeşitli hayvan denemelerinde belirlenen LD50 değerleri, $830 \mathrm{mg} / \mathrm{kg}$ ile 10 $\mathrm{g} / \mathrm{kg}$ vücut ağırlığı arasındadır. Normal olarak toprakta ve bitki dokularında da NTE bulunmaktadır. Sonuç olarak, ticari yemlerde, hayvan ve insan dokusunda da mevcuttur. Ayrıca, geleneksel yollarla yetiştirilen sebzelerde bulunan NTE içeriğinin, ek olarak NTE ile beslenen hayvanlardan elde edilen etlerden daha yüksek olduğu da gösterilmiştir. Bu nedenle, NTE'nin yem katkı maddesi olarak uygulanmasının insanlar için güvenli olduğu düşünülmektedir. Ayrıca mevcut bilgi birikimimize göre, tarımsal NTE uygulamalarının çevreye zararı beklenmemektedir. Aslında, NTE yem dönüşüm oranını iyileştirebildiği için, doğal kaynakların verimli kullanımını destekleyerek, çevresel yükü de azaltabilmektedir (3).

Mevcut araştırmalara göre, NTE bakteriyel mikro-ortamın yanı sıra besin alımı, sindirilebilirlik ve besin kullanım üzerindeki etkileri ile gastrointestinal sistem içerisinde yerel olarak etki göstermektedir. Anti-infammatory ve anti-oksidatif etkiler de pozitif etkilere katkıda bulunabilmektedir. Ayrıca, hücresel fonksiyonlar, büyüme ve sindirilebilirlikle ilgili hormonlar ve enzimler veya bağışıklık sistemi üzerindeki etkiler açısından ara metabolizma üzerindeki etkiler de tespit edilmiştir (3).

NTE takviyesinin ruminal fibrolitik ve proteolitik aktiviteleri iyileştirmenin yanı sıra, yenilebilir dokularda ihmal edilebilir kalıntı etkisine sahip şekilde et lezzetini de arttırdığ gösterilmiştir (6).

Yapılan bir çalışmada; $380 \mathrm{~g} / \mathrm{kg}$ ile $\mathrm{LaCI}_{3} \cdot 6 \mathrm{H}_{2} \mathrm{O}, 521 \mathrm{~g} / \mathrm{kg}$ ile $\mathrm{CeCI}_{3} \cdot 6 \mathrm{H}_{2} \mathrm{O}, 30 \mathrm{~g} / \mathrm{kg}$ ile $\mathrm{PrCI}_{3} \cdot 6 \mathrm{H}_{2} \mathrm{O}$ ve $69 \mathrm{~g} / \mathrm{kg}$ ile hafif NTE karışımı kullandığı bir besleme denemesi yapmışlardır. Araştırmada, yemin kuru madde bazında $885 \mathrm{~g} / \mathrm{kg}$ arpa danesi, $84 \mathrm{~g} / \mathrm{kg}$ arpa silajı ve $31 \mathrm{~g} /$ kg yem takviyesi eklendiğini rapor etmişlerdir. Farklı dozlarda NTE ilave edilen yemi (kontrol-ilave REE içermez; düşük-400 mg / kg NTE içerir; yüksek-800 mg / kg NTE içerir, kuru madde bazında), seyreltilmiş rumen sıvısında 4, 8, 14 ve 24 saat süreyle inkübe etmişlerdir. 24 saatlik inkübasyonun sonunda, artan NTE takviyesiyle gaz üretimi ve uçucu yağ asidi (VFA) konsantrasyonu doğrusal olarak arttığını; NTE desteğinin VFA profili üzerindeki etkisinin marjinal olduğunu tespit etmişlerdir. Kuru madde eksilmesi uygulamalardan etkilenmemiştir. Asetat (39.1) ve propiyonat (50.5) molar oranı (mol / 100 
mol), uygulamalarda benzer olmuştur. Bununla birlikte, butirat oranı (mol / 100 mol) yüksek NTE (6.6) uygulamasında, düşük NTE (5.3) veya kontrol (5.8) ile karşılaştırıldığında daha yüksek olmuştur. Organik maddenin (OM), ADF ve ham proteininin gerçek sindirilebilirliğgi, NTE takviyesi arttıkça doğrusal olarak artmıştır (7).

Nadir Toprak Elementinin etkisini incelemek için toplam 112 yeni sütten kesilmiş domuz yavru üzerinde 6 haftalık iki beslenme denemesi incelendiğinde (8) sütten kesme sonrası diyetlere, $200 \mathrm{mg} / \mathrm{kg}$ dozunda, bir NTE-sitrat lanthanum premiksi ve hafif lanthanoides seryum, praseodimyum ve neodim takviye etmişlerdir. Her iki denemede de, NTE-sitrat ve kontrol uygulamaları arasında, domuz yavrularının büyüme performansı önemli farklılık göstermemiştir.

Koyunlarda NTE'nin yem sindirilebilirliği, rumen fermentasyonu ve idrar pürin türevleri üzerindeki etkisini değerlendirmek için yapılan bir çalışma yapılmıştır (9). Koyunlar, kg kuru madde başına 100, 200 ve $300 \mathrm{mg}$ NTE-sitrat içeren bir bazal diyetle beslenmiştir. NTE karışımı seryum (\%56.8), lantan (\%35.0) ve praseodim (\%6.5) içermektedir. NTE takviyesi arttıkça ruminal $\mathrm{pH}$ değeri lineer ve kuadrik olarak ve amonyak N konsantrasyonu kuadrik olarak azalmış; toplam uçucu yağ asitleri konsantrasyonu doğrusal olarak artmıştır. Asetatın propiyonata oranı, propiyonat konsantrasyonunun artması nedeniyle lineer ve kuadratik olarak azalmıştır. Kuru madde, organik madde, NDF, ADF ve CP'nin sindirilebilirliği artan NTE ilavesiyle lineer ve kuadrik olarak artmıştır. Sonuç olarak, bazal diyetin NTE ile takviyesi, koyunlarda rumen fermantasyonunu ve yem sindirimini iyileştirmiştir. Optimum NTE takviye dozunun koyunlarda yaklaşık 200 mg / kg yem DM civarında olduğu tespit edilmiştir.

Farklı seviyelerde NTE'lerinin, Japon bıldırcınlarının büyüme performansına etkilerini belirlemek için bir çalışma yapılmıştır. Kontrol grubu bazal diyet (izonitrojen ve izokalorik) ile beslenmiş ve üç bıldırcın grubu bu bazal diyete ilave olarak 50,100 ve 200 mg / kg NTEsitrat, lantanit karışımı ile desteklenmiştir. NTE takviyeleri, kontrol grubuna kıyasla Japon bıldırcınlarının ağırlığını \%18.5-22 artırmıştır. Yem tüketimi ve yem dönüşümü uygulamalardan önemli ölçüde etkilenmemiştir. Bu çalışmanın sonuçlarına dayanarak, hem büyüme performanslarını hem de protein ve enerji kullanım verimliliğini artırmak için optimum NTE-sitrat konsantrasyon aralığ $50-100$ mg / kg yem olarak tespit edilmiştir (10). 


\section{ISSN2717-7238 ISPEC Journal of Agricultural Sciences}

\section{SONUÇ}

Nadir toprak elementleri içeren yem katkı maddeleri, İsviçre'de domuz üretimindeki kullanım için geçici izin alarak pazara girmiştir. 2016 yılında, Avrupa Birliği, ilk NTE bazlı yem katkı maddesine, sütten kesilmiş domuz yavruları için zooteknik bir katkı maddesi olarak izin vermiştir. Katkı maddesi olarak NTE ile yürütülmüş besleme çalışmalardan elde edilen sonuçlar, NTE kullanımının çiftlik hayvanlarında canlı ağırlık artışını ve yem dönüşümü oranını iyileştirdiğini göstermektedir. Araştırmalar, NTE karışımlarının domuz, sığır, koyun ve tavukların sadece canlı ağırlık kazanımlarını değil aynı zamanda süt ve yumurta üretimini de artırdığını göstermektedir. Sınırlı sayıda gerçekleştirilen denemeler temelinde kesin sonuçlar çıkarmak zordur, ancak kanatlı hayvan beslemede NTE, domuzlarda olduğu kadar umut verici bulunmamaktadır. Tekli NTE yerine NTE karışımıyla daha iyi etkiler elde edildiği görülmektedir. NTE'nin, klorürler formları yerine daha etkili olan organik tuzları daha başarılı bulunmaktadır.

\section{KAYNAKÇA}

1. Hanczakowska E Hanczakowski P 2010. Rare earth elements in farm animal feeding. Wiadomości Zootechniczne, 48(1): 15-20.

2. Rambeck W.A Wehr U 2005. Use of rare earth elements as feed additives in pig production. Pig News and Information, 26(2): 41-47

3. Redling K 2006. Rare earth elements in agriculture with emphasis on animal husbandry (Doctoral dissertation, lmu).

4. Abdelnour S.A El-Hack M.E A Khafaga A.F Noreldin A.E Arif M Chaudhry M.T Abdel-Daim M.M 2016. Impacts of rare earth elements on animal health and production: highlights of cerium and lanthanum. Science of the Total Environment 672: 1021-1031.

5. Squadrone S Stella C Brizio P Abete M.C 2016. A baseline study of the occurrence of rare earth elements in animal feed. Water, Air \& Soil Pollution, 229(6): 190. 


\section{ISSN2717-7238 ISPEC Journal of Agricultural Sciences}

6. Tariq H Sharma A Sarkar S Ojha L Pal R.P Mani V 2016. Perspectives of rare earth elements as feed additive in livestock: A review. Asian-Australasian Journal of Animal Sciences.

7. Yang W.Z Laarman A He M.L Liu Q 2009. Effect of rare earth elements on in vitro rumen microbial fermentation and feed digestion. Animal feed science and technology, 148(2-4), 227-240.

8. Kraatz M Taras D Männer K Simon O 2006. Weaning pig performance and faecal microbiota with and without in-feed addition of rare earth elements. Journal of Animal Physiology and Animal Nutrition, 90(9-10): 361-368.

9. Xun W Shi L Hou G Zhou H Yue W Zhang C Ren Y 2014. Effect of rare earth elements on feed digestibility, rumen fermentation, and purine derivatives in sheep. Italian Journal of Animal Science, 13(2): 3205.

10. Eleraky A.W Rambeck W 2011. Study on performance enhancing effect of rare earth elements as alternatives to antibiotic feed additives for Japanese quails. The Journal of American Science, 7(12): 211-215. 